\title{
Allergy to lidocaine injections: comparison of patient history with skin testing in five patients
}

\author{
Dorota Jenerowicz¹, Adriana Polańska', Olga Glińska², Magdalena Czarnecka-Operacz'1, Robert A. Schwartz ${ }^{3}$
}

1Department of Dermatology, Poznan University of Medical Sciences, Poznan, Poland

Head of Department: Prof. Zbigniew Adamski MD, PhD

2Department of Dermatology, Medical University of Warsaw, Poland

Head of Department: Prof. Lidia Rudnicka MD, PhD

${ }^{3}$ Dermatology and Pathology, New Jersey Medical School, Newark, New Jersey, USA

Head of Dermatology: Prof. Robert A. Schwartz MD, MPH

\begin{abstract}
Introduction: True allergy to local anesthetics, especially lidocaine, is uncommon. Most adverse reactions to this group of medications are classified as psychomotor, autonomic or toxic. In the case of suspected hypersensitivity to local anesthetics, skin testing is considered to be a useful tool - patch tests and intradermal tests for delayed hypersensitivity and skin prick tests and intradermal tests for immediate reactions. There is a particular need for such a diagnostic procedure, as patients suspected of hypersensitivity to local anesthetic drugs are frequently admitted.

Aim: To highlight the problem of hypersensitivity to local anesthetics on the basis of authors' own experience and literature data.

Material and methods: We present cases of 5 patients referred to the clinic by their dentists with a suspicion of allergy to local anesthetics, four to lidocaine and 1 to articaine.

Results: Intradermal tests were positive in 1 out of 5 subjects, with a concomitant episode of urticaria. In 1 patient we obtained a doubtful result of intradermal tests. Skin prick tests and patch tests were negative in all cases. In 2 cases we performed an incremental challenge test also with a negative result.

Conclusions: It has to be emphasized that, although rare, consequences of true allergy to local anesthetics can be serious considering a patient's future management and therapy. That is why this diagnosis may be crucial.
\end{abstract}

Key words: lidocaine, skin tests, incremental challenge test.

\section{Introduction}

Lidocaine represents the most common local anesthetic (LA) agent employed in local or regional anesthesia, included as a constituent of EMLA, a eutectic mixture of lidocaine and prilocaine [1, 2]. Although most allergic reactions are due to the common metabolic product of the ester local anesthetic, para-amino benzoic acid, cross-reactivity among esters is common. Ingredients in LA solutions such as antioxidants or preservatives including metabisulphite or parabens may also elicit allergic or adverse reactions. Articaine solutions should be avoided in those allergic or hypersensitive to sulphite, due to the content of sodium metabisulphite as the vasoconstrictor's antioxidant in it. The LA (without preservatives or adrenaline) may be skin tested.
True allergy to LA is rare, with a genuine immunological reaction representing only $1 \%$ of all adverse reactions to these medications [3-5]. In traditional classifications, adverse reactions to $L A$ have been categorized as allergic, toxic and autonomic [3]. Most of the patients undergoing dental procedures exhibit some degree of autonomic response to an injection, such as sweating, tachycardia or even syncope. However, it is usually mild and transient. Toxic reactions are mostly observed as a consequence of a rapid intra-vascular injection of LA or may be associated with an overdose in patients defectively metabolizing the drug.

There is undoubtedly a need for useful and reliable armamentarium in the diagnosis of allergy to lidocaine, as it is a common concern. What is more, the term "allergy" to LA is often easily accepted by the patient, who then expects it to be proven by available diagnostics. Many

Address for correspondence: Dorota Jenerowicz MD, PhD, Department of Dermatology, Poznan University of Medical Sciences, 49 Przybyszewskiego St, Poznań, phone: +48 6186915 68, e-mail: djenerowicz@yahoo.com

Received: 3.06.2013, accepted: 20.10.2013. 
times an adverse reaction took place several years prior to the testing with reliable documentation of the event lacking.

\section{Aim}

The aim of the paper is to highlight the problem of hypersensitivity to local anesthetics on the basis of authors' own experience and literature data.

\section{Material and methods}

We present 5 cases of patients ( 3 women and 2 men aged 19-50), admitted to the Department of Dermatology, Poznan University of Medical Sciences. All patients were referred to our Department by their dentists with a suspicion of allergy to LA. In the case of 4 patients, lidocaine was suspected as a culprit drug; in 1 case, articaine was suspected.

Three patients experienced an adverse reaction 2-2.5 months prior to diagnosis. In 2 subjects, the time interval between the reaction and diagnosis was much longer, being 17 and 25 years. Three patients had symptoms of an adverse reaction during a dental procedure involving the use of LA; 2 patients experienced an adverse reaction during tonsillectomy. In regards of the type of the adverse event, 2 patients experienced syncope, 1 had an episode of disseminated urticarial wheals and another had cardiac palpitations and anxiety. One female patient experienced an adverse reaction over 20 years earlier, for which there was no reliable documentation except the suggestion of a "severe immediate allergic reaction" by her family doctor.

A thorough case history was recorded with the use of the Polish version of the European Network of Drug Allergy (ENDA) questionnaire [6, 7]. Skin prick tests (SPT) with chosen LA, followed by intradermal tests (IDT) were performed using $1: 10$ 000, $1: 1000$ and $1: 100$ dilutions for lidocaine and $1: 10$ dilution for mepivacaine and articaine. We used LA preparations with no additional vasoconstrictors (e.g. epinephrine). All the procedures (STP followed by IDT if negative, dilution of examined medications) were performed thoroughly with the maximal safety considerations respected, especially in regards of possible immediate hypersensitivity reactions.

Histamine and normal saline served as a positive and negative control, respectively. The SPT was considered positive when the mean diameter of an allergen wheal was equal or slightly larger than the mean diameter of the histamine wheal (+++) and when the mean diameter of an allergen wheal was at least twice as big as the mean diameter of the histamine wheal $(++++)$ or in any case of response with pseudopodia (++++). The IDT was regarded positive if the diameter of an allergen wheal was at least $5 \mathrm{~mm}$. Both for SPT and IDT readings were performed after 15-20 min, 60 min and after $24 \mathrm{~h}$.

Patch tests (PT) were conducted with lidocaine 15\% and mepivacaine/articaine $1 \%$ dissolved in white petrolatum, using Finn Chambers applied on the back. Readings were performed after 48 and $72 \mathrm{~h}$ in accordance with the recommendations of the Polish Dermatological Society [8].

In 2 cases, a subcutaneous provocation test (incremental challenge test - ICT) with the use of Schatz protocol [9] was performed. Five consecutive subcutaneous injections were performed: $0.1 \mathrm{ml}(1: 100), 0.1 \mathrm{ml}(1: 10)$, $0.1 \mathrm{ml}(1: 1), 0.5 \mathrm{ml}(1: 1)$ and $1.0 \mathrm{ml}(1: 1)$.

\section{Results}

Out of 5 analyzed cases (Tables 1-5), patient number 3 presented with positive results of IDT with lidocaine in all examined dilutions, with a concomitant episode of disseminated urticarial wheals. Patient number 2 presented doubtful results of IDT with lidocaine $1: 10000$ and because of a probable history of a severe immediate reaction in the past, further diagnostic procedures were abandoned. In the case of patient number 1 (history of palpitations and sensation of fear after lidocaine injection), we could experience similar patient's complaints during performance of IDT with 1: 10000 dilution of the

Table 1. Results of skin tests - patient number 1

\begin{tabular}{|c|c|c|c|c|c|c|c|}
\hline & \multicolumn{4}{|c|}{$\begin{array}{c}\text { STPA }^{A} \text { and IDT } \\
\text { (erythema/wheal - diameter in } \mathrm{mm} \text { ) }\end{array}$} & \multicolumn{3}{|c|}{ PT (in white petrolatum) } \\
\hline & $\begin{array}{l}\text { Histamine: } 0 / 4 \\
\text { Normal saline: } 0 / 0\end{array}$ & $30 \mathrm{~min}$ & $60 \mathrm{~min}$ & $24 \mathrm{~h}$ & $\begin{array}{l}\text { White petrolatum: } \\
\text { negative }\end{array}$ & $48 \mathrm{~h}$ & $72 \mathrm{~h}$ \\
\hline \multirow[t]{3}{*}{ Lidocaine 2\% } & $1: 10000$ & $0 / 0^{A} 0 / 0^{B}$ & $0 / 0^{A} 0 / 0^{B}$ & $0 / 0^{A} 0 / 0^{B}$ & $15 \%$ & Not done & Not done \\
\hline & $1: 1000$ & \multirow{2}{*}{\multicolumn{3}{|c|}{$\begin{array}{c}\text { Further testing not done: fear, cardiac } \\
\text { palpitations, sweating (physical } \\
\text { examination: normal) }\end{array}$}} & & & \\
\hline & $1: 100$ & & & & & & \\
\hline Mepivacaine $3 \%$ & $1: 10$ & $0 / 0^{A} 0 / 0^{B}$ & $0 / 0^{A} 0 / 0^{B}$ & $0 / 0^{A} 0 / 0^{B}$ & $1 \%$ & Not done & Not done \\
\hline Articaine $4 \%$ & $1: 10$ & Not done & Not done & Not done & $1 \%$ & Not done & Not done \\
\hline Prilocaine & $1: 10$ & Not done & Not done & Not done & Not done & Not done & Not done \\
\hline Polidocanol & & Not done & Not done & Not done & $3 \%$ & Not done & Not done \\
\hline
\end{tabular}


Table 2. Results of skin tests - patient number 2

\begin{tabular}{|c|c|c|c|c|c|c|c|}
\hline & \multicolumn{4}{|c|}{$\begin{array}{c}\text { STPA }^{A} \text { and IDT } \\
\text { (erythema/wheal }- \text { diameter in } \mathrm{mm} \text { ) }\end{array}$} & \multicolumn{3}{|c|}{ PT (in white petrolatum) } \\
\hline & $\begin{array}{l}\text { Histamine: } 0 / 3 \\
\text { Normal saline: } 0 / 0\end{array}$ & $30 \mathrm{~min}$ & $60 \mathrm{~min}$ & $24 \mathrm{~h}$ & $\begin{array}{l}\text { White petrolatum: } \\
\text { negative }\end{array}$ & $48 \mathrm{~h}$ & $72 \mathrm{~h}$ \\
\hline \multirow[t]{3}{*}{ Lidocaine $2 \%$} & $1: 10000$ & $0 / 0^{A} 0 / 3^{B}$ & $0 / 0^{A} 0 / 2^{B}$ & $0 / 0 \mathrm{~A} 0 / 0^{B}$ & $15 \%$ & Negative & Negative \\
\hline & $1: 1000$ & Not done & Not done & Not done & & & \\
\hline & $1: 100$ & Not done & Not done & Not done & & & \\
\hline Mepivacaine 3\% & $1: 10$ & $0 / 0^{A} 0 / 0^{B}$ & $\mathrm{O} / \mathrm{O}^{\mathrm{A}} \mathrm{O} / \mathrm{OB}$ & $0 / 0^{A} 0 / 0^{B}$ & $1 \%$ & Negative & Negative \\
\hline Articaine $4 \%$ & $1: 10$ & $0 / 0^{A} 0 / 0^{B}$ & $0 / 0^{A} O / O B$ & $0 / 0^{A} 0 / 0^{B}$ & $1 \%$ & Not done & Not done \\
\hline Prilocaine & $1: 10$ & Not done & Not done & Not done & Not done & Not done & Not done \\
\hline Polidocanol & & Not done & Not done & Not done & $3 \%$ & Negative & Negative \\
\hline
\end{tabular}

Table 3. Results of skin tests - patient number 3

\begin{tabular}{|c|c|c|c|c|c|c|c|}
\hline & \multicolumn{4}{|c|}{$\begin{array}{c}\mathrm{STP}^{\mathrm{A}} \text { and IDT } \\
\text { (erythema/wheal - diameter in } \mathrm{mm} \text { ) }\end{array}$} & \multicolumn{3}{|c|}{ PT (in white petrolatum) } \\
\hline & $\begin{array}{l}\text { Histamine: } 10 / 5 \\
\text { Normal saline: } 0 / 0\end{array}$ & $30 \mathrm{~min}$ & $60 \mathrm{~min}$ & $24 \mathrm{~h}$ & $\begin{array}{c}\text { White petrolatum: } \\
\text { negative }\end{array}$ & $48 \mathrm{~h}$ & $72 \mathrm{~h}$ \\
\hline \multirow[t]{3}{*}{ Lidocaine $2 \%$} & $1: 10000$ & $0 / 0^{A} 25 / 5^{B}$ & $0 / 0^{A} 0 / 1^{B}$ & $0 / 0^{A} 0 / 0^{B}$ & $15 \%$ & Not done & Not done \\
\hline & $1: 1000$ & $0 / 0^{A} 20 / 4^{B}$ & $0 / 0^{A} 0 / 0^{B}$ & $0 / 0^{A} 0 / 0^{B}$ & & & \\
\hline & $1: 100$ & $0 / 0^{A} 25 / 5^{B}$ & $0 / 0^{A} 0 / 1^{B}$ & $0 / 0^{A} 0 / 0^{B}$ & & & \\
\hline Mepivacaine 3\% & $1: 10$ & Not done & Not done & Not done & $1 \%$ & Not done & Not done \\
\hline Articaine $4 \%$ & $1: 10$ & Not done & Not done & Not done & $1 \%$ & Not done & Not done \\
\hline Prilocaine & $1: 10$ & Not done & Not done & Not done & Not done & Not done & Not done \\
\hline Polidocanol & & Not done & Not done & Not done & $3 \%$ & Not done & Not done \\
\hline
\end{tabular}

The patient presented both positive IDT and an episode of disseminated urticarial wheals.

Table 4. Results of skin tests - patient number 4

\begin{tabular}{|c|c|c|c|c|c|c|c|}
\hline & \multicolumn{4}{|c|}{$\begin{array}{c}\mathrm{STP}^{\mathrm{A}} \text { and IDT } \\
\text { (erythema/wheal - diameter in } \mathrm{mm} \text { ) }\end{array}$} & \multicolumn{3}{|c|}{ PT (in white petrolatum) } \\
\hline & $\begin{array}{l}\text { Histamine: } 20 / 4 \\
\text { Normal saline: } 0 / 0\end{array}$ & $30 \mathrm{~min}$ & $60 \mathrm{~min}$ & $24 \mathrm{~h}$ & $\begin{array}{l}\text { White petrolatum: } \\
\text { negative }\end{array}$ & $48 \mathrm{~h}$ & $72 \mathrm{~h}$ \\
\hline \multirow[t]{3}{*}{ Lidocaine 2\% } & $1: 10000$ & $0 / 0^{A} 0 / 0^{B}$ & $0 / 0^{A} 0 / 0^{B}$ & $0 / 0^{A} 0 / 0^{B}$ & $15 \%$ & Negative & Negative \\
\hline & $1: 1000$ & $0 / 0^{A} 0 / 0^{B}$ & $0 / 0^{A} 0 / 0^{B}$ & $0 / 0^{A} 0 / 0^{B}$ & & & \\
\hline & $1: 100$ & $0 / 0^{A} 0 / 0^{B}$ & $0 / 0^{A} 0 / 0^{B}$ & $0 / 0^{A} 0 / 0^{B}$ & & & \\
\hline Mepivacaine 3\% & $1: 10$ & Not done & Not done & Not done & $1 \%$ & Negative & Negative \\
\hline Articaine 4\% & $1: 10$ & $0 / 0^{A} 0 / 0^{B}$ & $0 / 0^{A} 0 / 0^{B}$ & $0 / 0^{A} 0 / 0^{B}$ & $1 \%$ & Not done & Not done \\
\hline Prilocaine & $1: 10$ & Not done & Not done & Not done & Not done & Not done & Not done \\
\hline Polidocanol & & Not done & Not done & Not done & $3 \%$ & Negative & Negative \\
\hline
\end{tabular}

drug. Physical examination was normal, but the patient refused to be further tested.

Both SPT and PT were negative in all cases. The ICT with lidocaine and articaine conducted in the case of patients number 4 and 5 were negative.

\section{Discussion}

It is not unusual to elicit a history of allergy to LA. However, less than $1 \%$ of reported allergic reactions to these medications are immune system mediated. While obtaining a history, it often eventuates that the patient might have experienced rather a syncopal episode associated with an injection or cardiac palpitations due to action of epinephrine in administered solution or released endogenously. According to Wildsmith [10], among 25 patients initially diagnosed as being allergic to LA during dental treatment, 6 were diagnosed as suffering from phobia, panic or anxiety, 1 patient received an intravascular injection (adrenaline content of the cartridge), 
Table 5. Results of skin tests - patient number 5

\begin{tabular}{|c|c|c|c|c|c|c|c|}
\hline & \multicolumn{4}{|c|}{$\begin{array}{c}\text { STPA }^{\mathrm{A}} \text { and IDT } \\
\text { (erythema/wheal - diameter in } \mathrm{mm} \text { ) }\end{array}$} & \multicolumn{3}{|c|}{ PT (in white petrolatum) } \\
\hline & $\begin{array}{l}\text { Histamine: } 10 / 5 \\
\text { Normal saline: } 0 / 0\end{array}$ & $30 \mathrm{~min}$ & $60 \mathrm{~min}$ & $24 \mathrm{~h}$ & $\begin{array}{l}\text { White petrolatum: } \\
\text { negative }\end{array}$ & $48 \mathrm{~h}$ & $72 \mathrm{~h}$ \\
\hline \multirow[t]{3}{*}{ Lidocaine $2 \%$} & $1: 10000$ & $0 / 0^{A} 0 / 0^{B}$ & $0 / 0^{A} 0 / 0^{B}$ & $0 / 0^{A} 0 / 0^{B}$ & $15 \%$ & Negative & Negative \\
\hline & $1: 1000$ & $0 / 0^{A} 0 / 0^{B}$ & $0 / 0^{A} 0 / 0^{B}$ & $0 / 0^{A} 0 / 0^{B}$ & & & \\
\hline & $1: 100$ & $0 / 0^{A} 0 / 0^{B}$ & $0 / 0^{A} 0 / 0^{B}$ & $0 / 0^{A} 0 / 0^{B}$ & & & \\
\hline Mepivacaine 3\% & $1: 10$ & Not done & Not done & Not done & $1 \%$ & Negative & Negative \\
\hline Articaine 4\% & $1: 10$ & Not done & Not done & Not done & $1 \%$ & Not done & Not done \\
\hline Prilocaine & $1: 10$ & Not done & Not done & Not done & Not done & Not done & Not done \\
\hline Polidocanol & & Not done & Not done & Not done & $3 \%$ & Negative & Negative \\
\hline
\end{tabular}

1 patient appeared to be allergic to metabisulphite and latex allergy accounted for problems with 3 patients.

Allergic responses to LA are rare. In the majority of cases, hypersensitivity to this group of drugs may be excluded. It is suggested that the amide class of LA (lidocaine, mepivacaine, bupivacaine, articaine, prilocaine) is significantly less allergic than the ester type (benzocaine, procaine, tetracaine), There is also limited cross-reactivity between amide LA drugs [11]. However, according to data published by Zanni et al. [12], good agreement may be observed between clinical sensitization, PT and lymphocyte transformation test, indicating that there is a high degree of cross-reactivity between lidocaine and mepivacaine, also on the clonal level.

Among allergic reactions to LA, type IV hypersensitivity responses have been described predominantly to ester LA and clinically are represented by either contact dermatitis or rashes (macular or maculopapular) [13]. Torres et al. [14] also described the first case of fixed drug eruption induced by mepivacaine. This report was followed by others $[15,16]$. Contact allergy to amide anesthetics is rare and, according to Klein and Gall [17] in 1991, only 18 cases had been reported since these medications began to be used in the 1940s. Most of the delayed-type hypersensitivity reactions take place after a topical application of the drug [18]. There have been also reports of cases presenting as contact dermatitis due to subcutaneous administration of LA, which have been confirmed by patch testing. Bircher et al. [13] described a case of a delayed-type reaction to LA with subsequent positive PT to lidocaine, mepivacaine and prilocaine but negative to articaine. Kanerva et al. [19] described a case of a 48-year-old patient, who developed contact dermatitis after an infiltration with mepivacaine and lidocaine and they concluded that diagnostic approach of a patient suspected of delayed-type hypersensitivity to LA should include not only PT, but also IDT.

Immediate IgE-mediated allergic responses, particularly to amide type LA, are uncommon. According to some authors, in more than 30 years of their practice, there has never been verified an immediate allergic reaction to LA using available diagnostic technology [10]. However, there are case reports of adverse reactions to LA, suggesting type I hypersensitivity, where signs and symptoms tend to occur within minutes of drug injection and include urticaria, episodes of angioneurotic edema, wheezing, sneezing, pruritus or even anaphylactic shock $[3,10]$.

Bosco et al. [20] described a patient with an adverse reaction to a preparation of the amide local anesthetic prilocaine and epinephrine. Signs and symptoms were consistent with an anaphylactic reaction and the patient responded positively to treatment based on this assumption (epinephrine injected sublingually and oxygen by inhalation). However, subsequent skin testing failed to confirm this diagnosis. A final diagnosis of an anaphylactoid reaction was made. Seskin [21] reported on a case of an anaphylactic reaction during a routine dental appointment to an injection of mepivacaine hydrochloride $3 \%$ without a vasoconstrictor. Again an immediate medical treatment alleviated the symptoms and prevented a more profound collapse. The author suggested that the patient might have been sensitized during emergency treatment at a hospital at which time a local anesthetic was probably administered.

In the case of suspected true hypersensitivity to LA, skin tests are considered a useful tool for the diagnosis of sensitization to this group of drugs and also for the analysis of cross-reactivity patterns. In all of 5 analyzed cases, the adverse reaction after LA injection was immediate, but in regards of type I allergy, particularly suggestive for patient 3 with the history of urticaria. Indeed, the same patient occurred to present positive results of IDT and, moreover, had an episode of urticaria during conducted diagnostic procedures. In 1 patient, the results of IDT were doubtful; however, the 25 years between adverse reaction and testing could be an important factor influencing the result and explain why further diagnostic tests were stopped. The SPT were negative in all cases, so it was advisable that they should be followed by performing an IDT due to its higher sensitivity. For the rest of analyzed patients, psychomotor (either vasovagal and hyperventilation) responses should be considered. 
Our results are consistent with observations of other authors. Cuesta-Herranz et al. [22] described a patient who reacted to an unknown anesthetic for which the SPT were negative, but IDT gave an immediate reaction to mepivacaine, lidocaine and bupivacaine. Jacobsen et al. [23] examined 48 patients suspected of hypersensitivity to LA. Reactions ranged from dizziness and fainting to anaphylaxis. Suspected culprit drugs included lidocaine, bupivacaine, prilocaine and mepivacaine. Three patients representing 4 case histories tested positive on IDT (with lidocaine, and mepivacaine) - clinical manifestations included local swelling and general rash. All test-positive patients were females, none of them were atopic. It is worth emphasizing that neither 5 anamnestic cases of anaphylaxis referred by dentists nor 1 case of LA-induced asthma tested positive.

Lidocaine is a compound that does not cross-react with benzocaine [24]. Some patients allergic to lidocaine can tolerate procaine, prilocaine, or mepivacaine. The LA are considered as the most commonly used drugs in various branches of medicine.

\section{Conclusions}

Although true allergy to LA is a rare phenomenon, once an adverse reaction occurs, its nature should be thoroughly examined. Proper diagnostic procedures give the possibility to protect the patient from a severe, life-threatening future event, and on the other hand, draw attention to other possible causative factors of LA intolerance (phobia, hypersensitivity to preservatives and latex). This issue is even more important as it is estimated that in upcoming years an incidence of LA hypersensitivity will increase due to expanding use of this group of medications or due to possibility of re-exposure to various agents characterized by a similar chemical structure [25].

\section{Conflict of interest}

Authors report no conflict of interest.

\section{References}

1. Shipton EA. New formulations of local anaesthetics-part 1. Anesthesiol Res Pract 2012; 2012: 546409.

2. Dewachter P, Mouton-Faivre C, Emala CW. Anaphylaxis and anesthesia: controversies and new insights. Anesthesiology 2009; 111: 1141-50.

3. Wilson AW, Deacock S, Downie IP, Zaki G. Allergy to local anaesthetic: the importance of thorough investigation. $\mathrm{Br}$ Dental J 2000; 188: 120-2.

4. Rood JP. Adverse reaction to dental local anaesthetic injection - "allergy" is not the cause. Br Dent J 2000; 189: 380-5.

5. Finucane BT. Allergies to local anesthetics - the real truth. Can J Anesth 2003; 50: 869-74.

6. Demoly P, Kropf R, Bircher A, Pichler WJ. For the EAACI Interest Group on Drug Hypersensitivity. Drug hypersensitivity questionnaire. Allergy 1999; 54: 999-1003.
7. Jenerowicz D, Czarnecka-Operacz M, Silny W. Adverse drug reactions diagnostics - modification of the European Academy of Allergology and Clinical Immunology Interest Group on Drug Hypersensitivity and European Network of Drug Allergy questionnaire. Postep Derm Alergol 2005; 22: 112-8.

8. Spiewak R. Contact eczema. Postep Derm Alergol 2009; 26: 375-7.

9. Schatz M. Skin testing and incremental challenge in the evaluation of adverse reactions to local anaesthetics. JACI 1984; 74: 606-15.

10. Wildsmith JA. Hypersensitivity to local anaesthetics: a direct challenge test with lignocaine for definitive diagnosis. $\mathrm{Br}$ Med J 1982; 284: 1708.

11. Gonzalez-Delgado P, Anton R, Soriano V. Cross-reactivity among amide-type local anesthetics in a case of allergy to mepivacaine. J Investig Allergol Clin Immunol 2006; 16: 311-3.

12. Zanni MP, Mauri-Hellweg D, Brander C. Characterization of lidocaine-specific T cells. J Immunol 1997; 158: 1139-48.

13. Bircher AJ, Messmer SL, Surber C. Delayed-type hypersensitivity to subcutaneous lidocaine with tolerance to articaine: conformation by in vivo and in vitro tests. Contact Dermatitis 1996; 34: 387-9.

14. Torres MJ, Garcia JJ, del Cano Moratinos AM, et al. Fixed drug eruption induced by mepivacaine. J Allergy Clin Immunol 1995; 96: 130-1.

15. Takahama H. A fixed drug eruption that developed cross-sensitivity among amide local anaesthetics, including mepivacaine hydrochloride, lidocaine hydrochloride and propitocaine hydrochloride. J Eur Acad Dermatol Venereol 2008; 22: 1400-1.

16. Kawada A, Noguchi H, Hiruma M, et al. Fixed drug eruption induced by lidocaine. Contact Dermatitis 1996; 35: 375.

17. Klein CE, Gall H. Type IV allergy to amide-type local anesthetics. Contact Dermatitis 1991; 25: 45-8.

18. Sanchez-Morillas L, Martinez JJL, Martos MR, et al. Delayed-type hypersensitivity to mepivacaine with cross-reaction to lidocaine. Contact Dermatitis 2005; 53: 352-3.

19. Kanerva L, Alanko K, Estlander T, Jolanki R. Inconsistent intracutaneous and patch test results in a patient allergic to mepivacaine and prilocaine. Contact Dermatitis 1997; 39: 197-9.

20. Bosco DA, Haas DA, Young DR, Harrop KL. An anaphylactoid reaction following local anesthesia: a case report. Anesth Pain Control Dent 1993; 2: 89-93.

21. Seskin L. Anaphylaxis due to local anesthesia hypersensitivity: report of case. J Am Dent Assoc 1978; 76: 841-3.

22. Cuesta-Herranz J, De las Herraz M, Fernandez M, et al. Allergic reaction caused by local anaesthetic agents belonging to the amide group. J Allergy Clin Immunol 1997; 99: 427-8.

23. Jacobsen RB, Borch JE, Bindslev-Jensen C. Hypersensitivity to local anaesthetics. Allergy 2005; 60: 262-4.

24. Rietschel Rl. Fowler JF Jr. Fisher's contact dermatitis. 4th ed. Williams Wilkins, Baltimore 1995; 240-1.

25. Grzanka A, Misiolek H, Filipowska A, et al. Adverse reactions to local anaesthetics - allergy, toxic reactions or hypersensitivity. Anestezjol Intens Ter 2010; 42: 175-8. 